\title{
Future Directions for the Study of Suicide and Self- Injury
}

\section{Citation}

Nock, Matthew K. 2012. Future directions for the study of suicide and self-injury. Journal of Clinical Child and Adolescent Psychology 41(2): 255-259.

\section{Published Version}

doi:10.1080/15374416.2012.652001

\section{Permanent link}

http://nrs.harvard.edu/urn-3:HUL.InstRepos:10728849

\section{Terms of Use}

This article was downloaded from Harvard University's DASH repository, and is made available under the terms and conditions applicable to Open Access Policy Articles, as set forth at http:// nrs.harvard.edu/urn-3:HUL.InstRepos:dash.current.terms-of-use\#OAP

\section{Share Your Story}

The Harvard community has made this article openly available.

Please share how this access benefits you. Submit a story.

Accessibility 


\title{
Future Directions for the Study of Suicide and Self-Injury
}

\author{
Matthew K. Nock, Ph.D.
}

Harvard University

Correspondence: Matthew K. Nock, Ph.D., 33 Kirkland Street, Cambridge MA 02138; nock@wjh.harvard.edu. 
The death of a child is one of the most tragic events imaginable. Even more gut-wrenching is when a child intentionally chooses to end his or her own life in order to escape from unbearable suffering. Unfortunately, the occurrence of self-harm behaviors increases dramatically and occurs at elevated rates during adolescence (Nock, et al., 2008) and suicide currently is the fourth leading cause of all death among U.S. children and adolescents aged 10-14 years, third among those 15-24 years, and second among those 25-34 years (National Center for Health Statistics, 2011). As a parent, this state of affairs is unacceptable. As psychological scientists, we must do more to decrease this tragic loss of precious life.

Fortunately, the past few decades have brought significant advances in the understanding of suicide and other forms of self-inflicted injury. For instance, we have learned that suicidal behavior seems to run in families and the risk of suicidal behavior that is transmitted across generations exists above and beyond that of psychiatric disorders such as depression (Brent \& Mann, 2006; Gureje, et al., 2011). We also have learned that the experience of serious adversities during childhood significantly increases one's risk of the onset and persistence of suicidal behavior (Bruffaerts, et al., 2010; Dube, et al., 2001). We also are starting to see more complex models that examine the interaction of risk factors, such as those combining the findings mentioned above to suggest that some inherited genetic factors (e.g., a functional polymorphism of the serotonin transporter gene) may interact with environmental risk factors (e.g., childhood maltreatment) to increase the risk of depression and suicidal behavior (Caspi, et al., 2003) [although such models currently are being debated and re-examined in the literature; (Karg, Burmeister, Shedden, \& Sen; Risch, et al., 2009)].

Despite these and other important advances, there is still a great deal that remains unknown about even some of the most fundamental characteristics of self-harm. The enormous 
lacunae in our current understanding of self-harm provide a research agenda for future directions in the study of suicidal and nonsuicidal self-injury. In this paper, I outline what I perceive to be some of the most important future directions in this effort.

\section{What is self-harm?}

Over the past several years, there has been a great deal of discussion, and some debate, in the scientific and clinical community regarding what terms we should use to describe self-harm behaviors and how we should define them. For instance, terms like "parasuicide," "suicidality," and "deliberate self-harm" have been used inconsistently to refer to self-injury with no intention of dying and self-injury with the intention of dying - despite the fact that these are distinct behaviors with differing base rates, courses, correlates, and responsiveness to treatment. At this point, however, the discussion regarding what to call different self-harm behaviors has been largely resolved, with most researchers now making distinctions between suicidal self-injury (e.g., suicide ideation, suicide plans, suicide attempts, and suicide death) and nonsuicidal selfinjury (NSSI; i.e., direct, deliberate destruction of one's own body tissue in the absence of any intent to die).

Future efforts are needed to operationalize these constructs even more clearly and specifically. For example, many studies use as a primary dependent variable a person's "yes" vs. "no" response to individual items asking whether they have ever made a "suicide plan" or "suicide attempt." But what does it actually mean to make a suicide plan or attempt? Different people may interpret such questions in different ways, and indeed several recent studies suggest that this is happening. One recent study revealed that approximately $40 \%$ of people who respond "yes" to the question of whether they have ever attempted suicide report in a follow-up question that they did not intend to die from their behavior, suggesting that their definition of a "suicide 
attempt" differs dramatically from that of most researchers (Nock \& Kessler, 2006). Similarly, studies of NSSI use varying definitions of this behavior based on frequency and timeframe, with some using the definition that a person has engaged in one lifetime episode of NSSI, some requiring one episode in the past year, and others requiring multiple episodes in the past year. Such discrepancies lead to dramatic differences in prevalence estimates and sample selection, both of which can stunt scientific progress (e.g., imagine the problems that would arise in alcohol research if no distinction were made between those who had consumed one drink in their lifetime and those who drink heavily several times per week). Studies using clearer and more specific definitions are needed to increase the reliability and validity of findings from studies in this area. Furthermore, efforts to standardize the definitions used, such as the current proposal to include NSSI in DSM-5, will increase consistency across studies and will further facilitate research progress.

\section{How can we best measure self-harm?}

One of the greatest limitations in the study of self-harm is that the actual behaviors of interest - self-injurious thoughts and behaviors - are never observed directly. This is in stark contrast to how scientists work in most other fields in the natural and social sciences (e.g., chemistry, biology, economics, anthropology) and even in other areas of clinical psychology. In the study of depression, anxiety, psychosis, alcohol use, and other problems, researchers study people while they are experiencing the symptoms of interest in order to understand how, where, and why they occur. In contrast, because self-harm thoughts and behaviors are transient in nature and we cannot ethically induce them in the lab or even allow these behaviors to occur in such settings, researchers ask people to report on their self-injurious thoughts and behaviors using 
long-term retrospective recall. This failure to study the primary constructs of interest as they actually occur significantly limits the reliability and validity of our observations.

If we are to really understand self-harm, future research is needed to capture such thoughts and behaviors and study the individuals experiencing them as they actually occur in real-time. Importantly, recent technological advances provide the methods to make such studies possible. Several recent studies provide first steps toward this end by using ecological momentary assessment methods to examine the self-reported occurrence, frequency, severity, and immediate antecedents and consequences of episodes of self-injurious thoughts and behaviors (Armey, Crowther, \& Miller, 2011; Muehlenkamp, et al., 2009; Nock, Prinstein, \& Sterba, 2009). Another recently emerging line of research is using objective, behavioral tests to measure suicide-related cognitions among those currently thinking about suicide (Cha, Najmi, Park, Finn, \& Nock, 2010; Nock, Park, et al., 2010). These represent new directions in the measurement of self-harm that highlight some of the ways in which recent technological advances can be used to more directly and rigorously measure and study self-harm thoughts and behaviors.

\section{Who harms themselves?}

Recent research efforts have yielded valuable data on the epidemiology of suicidal behaviors. We now have rich, cross-national data on the prevalence, age-of-onset, course, persistence, risk factors, and treatment of suicidal behaviors around the globe (Nock, Borges, \& Ono, in press). Such information is important scientifically for understanding suicidal behaviors, clinically for identifying and treating them, and from a policy perspective for planning and allocating prevention and intervention resources. 
Future work is needed to provide similar data on NSSI. Although NSSI has been reported for thousands of years, systematic research on this problem has begun only in the past few decades. As a result, large-scale, long-term data on NSSI are not available. Moreover, most of the epidemiologic research on both suicidal and nonsuicidal self-injury that has been done has focused on adult samples, and much less is known about the epidemiology of self-harm among children and adolescents. Given the apparent increases in self-harm during adolescence, there is a strong need for more detailed information about the occurrence of self-harm during this developmental period. Studies such as the National Comorbidity Survey Replication Adolescent Supplement (Kessler, et al., 2009) can provide valuable initial data on self-harm during adolescence, and offer a point of departure for more intensive studies moving forward.

\section{Why do people harm themselves?}

We have learned a great deal about what factors increase the likelihood of suicidal and nonsuicidal self-injury over the past several decades, but much less about how or why they do so. We know that in the U.S., being white, male, and having a mental disorder all significantly increase one's risk of suicide (e.g., $85 \%$ of suicides are white, $80 \%$ are male, and $90-95 \%$ have a mental disorder) (Cavanagh, Carson, Sharpe, \& Lawrie, 2003; Centers for Disease Control and Prevention, 2011). However, we lack a firm understanding of how or why each of these factors increases the risk of suicide. Developing and testing theoretically-driven and empiricallysupported models of how and why well-known risk factors lead to self-harm is one of the most important directions for future research in this area (Brent, 2011; Nock, 2009a, 2009b).

There are myriad directions in which research can progress in this area. Several particular paths are especially important to follow. First, research will proceed most clearly and efficiently if explanatory models of self-harm are focused on the prediction of specific self-injurious 
outcomes. As an example, it has long been known that depression is associated with increased risk of suicide ideation, attempt, and death. However, recent studies have shown that although depression is a strong predictor of suicide ideation, it does not predict which people with ideation go on to make a suicide attempt. Instead, it is psychiatric disorders characterized by anxiety, agitation, and poor behavioral control that best predict the transition from ideation to attempt (Nock, Hwang, Sampson, \& Kessler, 2010). Examining which risk factors are associated with each part of the pathway to suicidal and nonsuicidal self-injury will help us to start to make sense of the many risk factors that have been identified, and also will yield the most clinically useful information.

Second, once we have clearer data on the associations between risk factors and specific self-harm outcomes, research is needed to better understand the causal mechanisms through which known risk factors increase the likelihood of self-harm (Brent, 2011; Nock, 2009a). As a field, we lack any fine-grained understanding of the causal mechanisms or pathways through which known risk factors lead to self-harm. Obtaining a better understanding of such mechanisms is important not only for enhancing scientific understanding of these outcomes, but for predicting and preventing them as well. How and why does depression lead to suicide ideation? How and why do disorders such as posttraumatic stress disorder, conduct disorder, and substance use disorders lead to suicide attempts? If we learn, for example, that substance use disorders are associated with suicide attempts because of the associated higher levels of trait impulsiveness, this suggests that we might test interventions targeting impulsiveness in order to decrease the risk of suicide attempts rather than attempting to decrease the intake of substances. Indeed, if we know more clearly why it is that people become self-injurious, we will be much 
more accurate in identifying those at risk and much more effective in treating them given our ability to target the specific pathway identified.

Third, at the same time, future research also must do a much better job of examining the ways in which different risk factors work together to produce self-harm. Everyone agrees that suicide and NSSI are multi-determined outcomes that likely arise from the complex interaction of multiple factors. Yet, most studies examine bivariate, linear associations between individual risk factors and self-harm. Most individual risk factors over-predict self-harm (e.g., most people who die by suicide are men with a mental disorder, but most men with mental disorders do not attempt suicide). Thus, it is likely that the accurate prediction of self-harm requires models that simultaneously consider multiple risk factors. Such models may test the accumulation or interaction of risk factors from the same domain (e.g., depression x impulse-control disorders) or across different domains (e.g., genetic factors $\mathrm{x}$ environmental factors). The important thing is that we begin to increase the complexity of the models under examination in order to consider all available information in concert.

\section{How can we best predict, treat, and prevent self-harm?}

The ultimate goal of research on self-harm is to prevent it from occurring. Unfortunately, there currently are no evidence-based methods available for treating or preventing adolescent suicidal or nonsuicidal self-injury. As in other areas, here too there are some promising leads.

One vital direction for future research is to improve our ability to predict self-harm. We already have information on dozens of risk factors from prior research; however, there has been a surprising lack of research aimed at integrating this information into a useful format/algorithm for making predictions about the future risk of self-harm. Such an effort could take known risk and protective factors, develop different methods for integrating and weighting this information, 
and follow youth at risk over time to determine the best (i.e., most accurate) method of classifying risk level. That information could then be given to clinicians who could use it to: screen children and adolescents, assign them a risk score, and respond appropriately, with an evaluation component measuring the usefulness of such an approach for increasing the rate of referrals and decreasing the occurrence of self-harm behaviors. This all could be done with currently available information; however, to my knowledge, no such line of research exists.

Another very important direction is the development of evidence-based treatments for adolescent self-harm. To date, several intervention approaches, such as cognitive behavior therapy and multisystemic therapy, have shown an ability to decrease the risk of suicide attempt among youth (Esposito-Smythers, Spirito, Kahler, Hunt, \& Monti; Huey, et al., 2004). These studies require replication in order to meet the criteria for classification as evidence-based treatments; however, these initial results are encouraging and suggest that psychological interventions can reduce the risk of self-harm. In addition to testing these and other existing treatment packages, work is needed aimed at testing individual treatment components (including those that make up existing treatments as well as newer or previously untested approaches) to help identify active ingredients of psychological interventions. Initial studies should make use of single-case experiments to facilitate rapid and flexible treatment development and evaluation efforts (Barlow \& Nock, 2009). Such studies could be followed up by randomized controlled trials to further test the efficacy of interventions that show promise in earlier testing, and to examine potential mechanisms and moderators of change. There have been exciting advances in treatment development and evaluation in the past several years (Kazdin, 2011; Weisz, et al., 2011), and future research on the treatment of self-harm should make full use of them in order to maximize the fruits of these efforts. 
Yet another crucial direction is the development and evaluation of effective prevention programs. Here too, there have been some exciting recent findings, such as those showing that school-based prevention programs can decrease the risk of suicide attempts (Aseltine \& DeMartino, 2004). There are a lot of prevention programs used in practice, many of them aimed at increasing public awareness and education about suicide and self-injury. Unfortunately, most have not been evaluated and as a result we do not have a firm understanding of which, if any, will be effective in preventing suicide and self-injury (Mann, et al., 2005). Thus, there is a tremendous need for future research on the prevention of self-harm.

By themselves, approaches like individual psychotherapy and school-based prevention programs will not be sufficient to prevent self-harm. Given the scope and seriousness of these problems, coupled with the fact that most people who engage in self-harm do not present for treatment (e.g., Bruffaerts, et al., 2011), we will need a full portfolio of preventive models and methods to combat this problem (Kazdin \& Blase, 2011). The purpose of the recently created National Action Alliance for Suicide Prevention (http://actionallianceforsuicideprevention.org/) is to do just that - to make suicide prevention a national priority and to coordinate efforts to prevent it. If effective, we may be about to witness a vital turning point in the history of suicidal behavior and self-injury among youth. The choice is ours.

\section{Conclusions}

Suicidal and nonsuicidal self-injury continue to be absolutely devastating problems among children and adolescents. We have learned a great deal about these behaviors over the past several decades; however, despite this knowledge: rates of self-harm remain high, we lack a firm understanding of why people engage in these behaviors, and we do not have effective methods of accurately predicting or preventing these problems. For these reasons, it is vital that 
we ramp up efforts to fill in the gaps in our knowledge base in order to be better able to prevent these destructive behaviors. This paper described some potential directions for future research on suicidal and nonsuicidal self-injury. Whatever the specific directions we take-it is imperative that we act quickly, strongly, creatively, and comprehensively so that we can begin to decrease the tragic injury and loss of life due to suicide and self-injury. 


\section{References}

Armey, M. F., Crowther, J. H., \& Miller, I. W. (2011). Changes in ecological momentary assessment reported affect associated with episodes of nonsuicidal self-injury. Behav Ther, 42(4), 579-588.

Aseltine, R. H., Jr., \& DeMartino, R. (2004). An outcome evaluation of the SOS Suicide Prevention Program. Am J Public Health, 94(3), 446-451.

Barlow, D. H., \& Nock, M. K. (2009). Why can't we be more idiographic in our research? Perspectives on Psychological Science, 4, 19-21.

Brent, D. A. (2011). Preventing youth suicide: Time to ask how. J Am Acad Child Adolesc Psychiatry, 50(8), 738-740.

Brent, D. A., \& Mann, J. J. (2006). Familial pathways to suicidal behavior--understanding and preventing suicide among adolescents. N Engl J Med, 355(26), 2719-2721.

Bruffaerts, R., Demyttenaere, K., Borges, G., Haro, J. M., Chiu, W. T., Hwang, I., et al. (2010). Childhood adversities as risk factors for onset and persistence of suicidal behaviour. $\mathrm{Br} J$ Psychiatry, 197(1), 20-27.

Bruffaerts, R., Demyttenaere, K., Hwang, I., Chiu, W. T., Sampson, N., Kessler, R. C., et al. (2011). Treatment of suicidal people around the world. Br J Psychiatry, 199, 64-70.

Caspi, A., Sugden, K., Moffitt, T. E., Taylor, A., Craig, I. W., Harrington, H., et al. (2003). Influence of life stress on depression: Moderation by a polymorphism in the 5-HTT gene. Science, 301(5631), 386-389.

Cavanagh, J. T., Carson, A. J., Sharpe, M., \& Lawrie, S. M. (2003). Psychological autopsy studies of suicide: a systematic review. Psychol Med, 33(3), 395-405. 
Centers for Disease Control and Prevention (2011). Injury Prevention \& Control: Data and Statistics (WISQARS) Retrieved December 12, 2011, 2011, from http://www.cdc.gov/injury/wisqars/index.html

Cha, C. B., Najmi, S., Park, J. M., Finn, C. T., \& Nock, M. K. (2010). Attentional bias toward suicide-related stimuli predicts suicidal behavior. J Abnorm Psychol, 119(3), 616-622.

Dube, S. R., Anda, R. F., Felitti, V. J., Chapman, D. P., Williamson, D. F., \& Giles, W. H. (2001). Childhood abuse, household dysfunction, and the risk of attempted suicide throughout the life span: Findings from the Adverse Childhood Experiences Study. JAMA, 286(24), 3089-3096.

Esposito-Smythers, C., Spirito, A., Kahler, C. W., Hunt, J., \& Monti, P. Treatment of cooccurring substance abuse and suicidality among adolescents: A randomized trial. $J$ Consult Clin Psychol, 79(6), 728-739.

Gureje, O., Oladeji, B., Hwang, I., Chiu, W. T., Kessler, R. C., Sampson, N. A., et al. (2011). Parental psychopathology and the risk of suicidal behavior in their offspring: results from the World Mental Health surveys. Mol Psychiatry, 16, 1221-1233.

Huey, S. J., Jr., Henggeler, S. W., Rowland, M. D., Halliday-Boykins, C. A., Cunningham, P. B., Pickrel, S. G., et al. (2004). Multisystemic therapy effects on attempted suicide by youths presenting psychiatric emergencies. J Am Acad Child Adolesc Psychiatry, 43(2), 183190.

Karg, K., Burmeister, M., Shedden, K., \& Sen, S. The serotonin transporter promoter variant (5HTTLPR), stress, and depression meta-analysis revisited: Evidence of genetic moderation. Arch Gen Psychiatry, 68(5), 444-454. 
Kazdin, A. E. (2011). Evidence-based treatment research: Advances, limitations, and next steps. Am Psychol, 66(8), 685-698.

Kazdin, A. E., \& Blase, S. L. (2011). Rebooting psychotherapy research and practice to reduce the burden of mental illness. Perspectives on Psychological Science, 6, 21-37.

Kessler, R. C., Avenevoli, S., Costello, E. J., Green, J. G., Gruber, M. J., Heeringa, S., et al. (2009). National comorbidity survey replication adolescent supplement (NCS-A): II. Overview and design. J Am Acad Child Adolesc Psychiatry, 48(4), 380-385.

Mann, J. J., Apter, A., Bertolote, J., Beautrais, A., Currier, D., Haas, A., et al. (2005). Suicide prevention strategies: A systematic review. JAMA, 294(16), 2064-2074.

Muehlenkamp, J. J., Engel, S. G., Wadeson, A., Crosby, R. D., Wonderlich, S. A., Simonich, H., et al. (2009). Emotional states preceding and following acts of non-suicidal self-injury in bulimia nervosa patients. Behav Res Ther, 47(1), 83-87.

National Center for Health Statistics (2011). 10 Leading Causes of Death, United States; 2007 Retrieved December 9, 2011, from http://webappa.cdc.gov/cgi-bin/broker.exe

Nock, M. K. (2009a). Suicidal behavior among adolescents: Correlates, confounds, and (the search for) causal mechanisms. J Am Acad Child Adolesc Psychiatry, 48(3), 237-239.

Nock, M. K. (2009b). Why do People Hurt Themselves? New Insights Into the Nature and Functions of Self-Injury. Curr Dir Psychol Sci, 18(2), 78-83.

Nock, M. K., Borges, G., Bromet, E. J., Alonso, J., Angermeyer, M., Beautrais, A., et al. (2008). Cross-national prevalence and risk factors for suicidal ideation, plans and attempts. $\mathrm{Br} J$ Psychiatry, 192(2), 98-105.

Nock, M. K., Borges, G., \& Ono, Y. (Eds.). (in press). Suicide: Global perspectives from the WHO World Mental Health Surveys. New York: Cambridge University Press. 
Nock, M. K., Hwang, I., Sampson, N. A., \& Kessler, R. C. (2010). Mental disorders, comorbidity and suicidal behavior: results from the National Comorbidity Survey Replication. Mol Psychiatry, 15(8), 868-876.

Nock, M. K., \& Kessler, R. C. (2006). Prevalence of and risk factors for suicide attempts versus suicide gestures: Analysis of the National Comorbidity Survey. J Abnorm Psychol, $115(3), 616-623$.

Nock, M. K., Park, J. M., Finn, C. T., Deliberto, T. L., Dour, H. J., \& Banaji, M. R. (2010). Measuring the suicidal mind: Implicit cognition predicts suicidal behavior. Psychological Science, 21(4), 511-517.

Nock, M. K., Prinstein, M. J., \& Sterba, S. K. (2009). Revealing the form and function of selfinjurious thoughts and behaviors: A real-time ecological assessment study among adolescents and young adults. J Abnorm Psychol, 118(4), 816-827.

Risch, N., Herrell, R., Lehner, T., Liang, K. Y., Eaves, L., Hoh, J., et al. (2009). Interaction between the serotonin transporter gene (5-HTTLPR), stressful life events, and risk of depression: A meta-analysis. JAMA, 301(23), 2462-2471.

Weisz, J. R., Chorpita, B. F., Palinkas, L. A., Schoenwald, S. K., Miranda, J., Bearman, S. K., et al. (2011). Testing Standard and Modular Designs for Psychotherapy Treating Depression, Anxiety, and Conduct Problems in Youth: A Randomized Effectiveness Trial. Arch Gen Psychiatry. 